\title{
Wound healing activities of different extracts of Centella asiatica in incision and burn wound models: an experimental animal study
}

\author{
Juraiporn Somboonwong ${ }^{1}$, Mattana Kankaisre ${ }^{2}$, Boonyong Tantisira ${ }^{3}$ and Mayuree H Tantisira ${ }^{3,4^{*}}$
}

\begin{abstract}
Background: The efficacy of Centella asiatica for incision and burn wounds are not fully understood. Here, we report the wound healing activities of sequential hexane, ethyl acetate, methanol, and water extracts of Centella asiatica in incision and partial-thickness burn wound models in rats.

Methods: Male Sprague-Dawley rats weighing 250-300 g were randomly divided into incision and burn wound groups. Each group was stratified into seven subgroups: (1) untreated; (2) NSS-; (3) Tween $20^{\circledR}$ - (vehicle control); (4) hexane extract-; (5) ethyl acetate extract-; (6) methanol extract-; and (7) aqueous extract-treated groups. The test substances were applied topically once daily. The tensile strength of the incision wound was measured on the seventh day after wound infliction. The general appearance and degree of wound healing of the burn wound were assessed on Days 3, 7, 10 and 14 after burn injury and prior to histopathological evaluation.

Results: On the seventh day after wound infliction, the tensile strength of incision wound in all extract-treated groups was significantly higher than that of the vehicle control (Tween $20^{\circledR}$ ), but comparable to the NSS-treated group. The degrees of healing in the burn wound with the four extracts were significantly higher than that of the control on Days 3, 10 and 14. Histopathological findings on Day 14 after burn injury revealed prominent fibrinoid necrosis and incomplete epithelialization in the control and untreated groups, whereas fully developed epithelialization and keratinization were observed in all extract-treated groups. Analysis by thin layer chromatography demonstrated that the phyto-constituents $\beta$-sitosterol, asiatic acid, and asiaticoside and madecassocide were present in the hexane, ethyl acetate and methanol extracts, respectively.
\end{abstract}

Conclusions: All extracts of Centella asiatica facilitate the wound healing process in both incision and burn wounds. Asiatic acid in the ethyl acetate extract seemed to be the most active component for healing the wound.

Keywords: Centella asiatica, Wound healing, Incision wound, Burn wound, Asiatic acid, $\beta$-sitosterol, Asiaticoside, Madecassocide

\section{Background}

A wound is an injury to a part of the body, especially one in which a break is made in the skin. There are various types of wounds, including an incised wound, lacerated wound, abrasion, contusion, ulcer, and burn wound [1]. Treatment of the wound usually involves preventing infection because the skin, the body's barrier to infection, is

\footnotetext{
* Correspondence: Mayuree.t@chula.ac.th

${ }^{3}$ Department of Pharmacology and Physiology, Faculty of Pharmaceutical Sciences, Chulalongkorn University, Patumwan, Bangkok 10330, Thailand ${ }^{4}$ Present address: Faculty of Pharmaceutical Sciences, Burapha University, Chonburi 20131, Thailand

Full list of author information is available at the end of the article
}

destroyed. Burn wounds require treatment according to the severity of the burn. Minor burns are generally treated with topical ointment and dressing, while severe burns need immediate medical attention and hospitalization [2]. Inappropriate caring of the wound may delay its healing, causing the area to become infected and subsequently resulting in chronic wounds. Antimicrobial ointments such as silver sulfadiazine, mafenide, silver nitrate, povidone-iodine, mupirocin and bacitracin, are used to reduce the risk of infection in minor cuts and burns. However, these topical antimicrobials have some side effects and are only partially effective in healing the wound [3]. Hence, there is a need for newer drugs to heal the wound.

\section{Biomed Central}

(c) 2012 Somboonwong et al.; licensee BioMed Central Ltd. This is an Open Access article distributed under the terms of the Creative Commons Attribution License (http://creativecommons.org/licenses/by/2.0), which permits unrestricted use, distribution, and reproduction in any medium, provided the original work is properly cited. 
Development of drugs or agents to treat wounds has been performed for many years. Currently, several medicinal plants have been integrated into the health care system, especially the primary healthcare system [4]. One of the plants studied is the Centella asiatica (Linn.) Urban. This plant is commonly found in many parts of the world, including Asia and the Middle East [5]. In Asia, C. asiatica has long been used in traditional medicine because of its ability to heal wounds, improve mental clarity, and treat skin conditions such as leprosy and psoriasis [6]. The therapeutic substances in C. asiatica are saponin-containing triterpene acids and their sugar esters, of which asiatic acid, madecassic acid and asiaticosides are considered to be the most important [7].

It has been reported that $1 \%$ C. asiatica extract cream improves wound healing of chronic ulcer in width, length and depth after 7,14 and 21 days of use of the product [8]. In one study of the effect of $C$. asiatica extract on acute radiation dermatitis in rats, the wounds in the treatment group were less severe and the repair processes began earlier than those in the control group [9]. A study in an incision wound model demonstrated that the ethanolic extract of $C$. asiatica significantly increased the wound breaking strength [10]. Phyto-constituents present in $C$. asiatica have been found to be responsible for these wound healing properties. Asiaticoside isolated from $C$. asiatica increased hydroxyproline content, tensile strength, collagen content and epithelialization in a punch wound model [11]. Furthermore, triterpenes from C. asiatica were shown to increase remodeling of the collagen matrix and stimulate glycosaminoglycan synthesis in a rat wound chamber model [12]. Oral administration of madecassoside $(6,12,24 \mathrm{mg} / \mathrm{kg})$ isolated from $C$. asiatica herbs facilitated burn wound healing in mice through its antioxidative activity, collagen synthesis and angiogenesis [13]. In addition, an oral C. asiatica extract capsule has been proved to be effective in promotion of wound healing and scar suppression in patients with diabetes-related wounds, with no serious side effects [14].

Few studies have investigated the efficacy of $C$. asiatica on incision and burn wounds, which have different healing mechanisms compared to excision wounds. Thus, the purpose of this study was to evaluate the wound healing activities of sequential hexane, ethyl acetate, methanol, and aqueous extracts of $C$. asiatica in incision and partial-thickness burn wound models in rats.

\section{Methods}

\section{Preparation and extraction of C. asiatica}

Collected aerial parts of $C$. asiatica were oven-dried at $50^{\circ} \mathrm{C}$ and then powdered using a milling machine. The powdered plant $(1 \mathrm{~kg})$ was macerated with $n$-hexane $(3 \times 4$ L, 3 days each) at room temperature. The pooled filtrates were dried under reduced pressure to give the $n$-hexane extract (HexE) at a constant weight of $17.8 \mathrm{~g}$ ( $0.18 \%$ yield of fresh plant). The marc was air-dried before it was further macerated with ethyl acetate and methanol, respectively, using the procedure described above to give the ethyl acetate (EtAcE, $32.7 \mathrm{~g}, 0.33 \%$ yield) and methanol (MeE, 267.5 g, 2.68\% yield) extracts. Subsequently, a portion (300 g) of the dried marc was boiled in distilled water ( $2 \mathrm{~L}$ ) for $3 \mathrm{~h}$, then filtered and dried to give $95.1 \mathrm{~g}$ of the hot aqueous extract (AqE, $3.17 \%$ yield). All solvents used were of commercial grade and were obtained from U \& V Holding Ltd., Bangkok, Thailand.

Tween $20^{\circledR}$ (polyoxyethylene (20) sorbitan monolaurate) as a $10 \%$ solution in distilled water was used as vehicle for preparation of a $10 \%(\mathrm{w} / \mathrm{v})$ of each extract for topical application. Ten grams of the dried extract was triturated with $9 \mathrm{~mL}$ of vehicle. Vehicle was then added gradually until the final concentration of the extract was $10 \%$.

\section{Thin layer chromatography (TLC) profiling of the extracts} Characterization of the extracts was performed by TLC with a silica gel $60 \mathrm{~F}_{254}$ plate. The solvent systems used for analysis of HexE, EtAcE, MeE, and AqE were as follows: chloroform: acetate (9:1), chloroform: methanol (9:1), ethyl acetate: methanol: water (4:0.4:0.2) and ethyl acetate: methanol: water (4:0.4:0.3), respectively. The TLC plate for each extract was sprayed with $10 \%$ sulfuric acid in ethanol and then heated on a hot plate at a constant temperature of $100^{\circ} \mathrm{C}$ for $15 \mathrm{~min}$.

\section{Experimental protocol}

A total of 112 male Sprague-Dawley rats weighing 250$300 \mathrm{~g}$ obtained from the National Laboratory Animal Center, Mahidol University, Nakornpathom, Thailand were used in this study. The rats were caged in special rooms with a temperature of $25 \pm 1^{\circ} \mathrm{C}$, free access to commercial pellet diet and water ad libitum. The rats were used 7 days after arrival in the animal facility. This 7-day period allowed the animals to acclimatize to the laboratory environment. Animal experiments in this study were carried out in accordance with the ARRIVE (Animals in Research: Reporting In Vivo Experiments) guidelines [15] and the Guide for the Care and Use of Laboratory Animals of the National Research Council of Thailand. All care was taken to minimise the suffering of the animals. The experimental protocol was approved by the Ethics Committee of the Faculty of Pharmaceutical Sciences, Chulalongkorn University.

The animals were randomly divided into incision and burn wound groups with each group having 56 animals. Each group was further divided into seven subgroups composed of eight animals per subgroup: 1) untreated group, 2) NSS-treated group, 3) Tween $20^{\circledR}$-treated 
(vehicle control) group, 4) HexE-treated group, 5) EtAcE-treated group, 6) MeE-treated group, and 7) AqE-treated group.

Effect of $C$. asiatica extracts on healing of incision wounds The effect of Centella asiatica extracts on the healing of incision wounds was investigated by using the model of Baie and Shiekh [16]. The animals were anesthetized intraperitoneally with sodium pentobarbital at $60 \mathrm{mg} / \mathrm{kg}$ BW during induction of the wound. The right side on the back of each animal was shaved and depilated. Next, a $3 \mathrm{~cm}$ long, midline incision was made through the skin with a sharp scalpel and was closed with a $0.5 \mathrm{~cm}$ spaced interrupted sutures with black silk no.3-0 to secure the edges. After creating the wound, $0.5 \mathrm{~mL}$ of the test substance was topically applied to the affected area once daily. On the seventh day after inflicting the wound, the animals were sacrificed with intra-peritoneal injection of sodium pentobarbital at $100 \mathrm{mg} / \mathrm{kg}$ BW. Sutures were removed and tissues were isolated from the healed wound to assess its tensile strength, as described below.

\section{Assessment of the tensile strength of incision wounds}

Healing of incision wounds was evaluated by measuring the tensile strength on day 7 after inflicting the wound. Sutures were removed and the skin tissue was cut $1 \mathrm{~cm}$ away from each side of the wound. The isolated wound tissues were used to measure the load (force) required to break the tissue with a computerized tensiometer (EZTEST I 30804100798, Shimadzu Corp., Japan). Tensile strength was calculated using the following formula: tensile strength $\left(\mathrm{N} / \mathrm{cm}^{2}\right)=$ breaking force $(\mathrm{N}) /$ area $\left(\mathrm{cm}^{2}\right)$; where area $\left(\mathrm{cm}^{2}\right)=$ thickness $(\mathrm{cm}) \times$ width $(\mathrm{cm})[16]$.

\section{Effect of C. asiatica extracts on healing of burn wounds} The effect of $C$. asiatica extracts on the healing of the burn wounds was investigated using the method described by Somboonwong et al. [17], which was modified from Zawacki [18]. The animals were anesthetized with intra-peritoneal injection of sodium pentobarbital at $60 \mathrm{mg} / \mathrm{kg} \mathrm{BW}$ during induction of the wound. The back of the animal between the lower parts of both scapulas were shaved and depilated. Next, a partial thickness burn was made by putting a hot plate $(3.5 \times 4.6 \mathrm{~cm})$ at a temperature of $75^{\circ} \mathrm{C}$ on the prepared area for $10 \mathrm{~s}$. The burnt area was about $10 \%$ of the total body surface area. After burning, $0.5 \mathrm{ml}$ of the test substances was topically applied to the burnt area once daily. The burnt area was measured immediately after the burn and on Days 3, 7, 10 and 14 after burn injury using millimeter-scale graph paper. The degree of wound healing was calculated as described below. On day 14 after burn injury, the animals were sacrificed with intra-peritoneal injection of sodium pentobarbital at $100 \mathrm{mg} / \mathrm{kg} \mathrm{BW}$. Tissue of the healed wound $(0.5 \times 0.5 \mathrm{~cm})$ was collected from each animal for histological examination.

\section{Gross examination of the burn wound lesion}

The wound was grossly examined on Days 3, 7, 10 and 14 after burn injury. The lesion of the wounds was examined using the following criteria: wound bed, color, exudates, swelling of the wound surface, and the consistency of tissues surrounding the wound.

\section{Assessment of the degree of healing of burn wounds}

On Days 3, 7, 10 and 14 after burn injury, color photographs of the wounds were taken by digital camera. The areas of the wound were measured by tracing the wound boundaries using millimeter-scale transparent graph paper with a permanent marker. The degree of wound healing was calculated using the following formula: degree of wound healing $(\%)=1$-[wound area on the corresponding day $\left(\mathrm{cm}^{2}\right) /$ wound area on day zero $\left.\left(\mathrm{cm}^{2}\right)\right] \times 100$ [19].

\section{Histopathological examination of burn wounds}

A specimen of the skin $(0.5 \times 0.5 \mathrm{~cm})$ was taken from the middle of the burnt area. The tissue was preserved in a $10 \%$ fresh, neutral buffered solution of formaldehyde for at least $24 \mathrm{~h}$. Sections were stained with hematoxylin and eosin dyes and examined using a light microscope (Nikon 516609) with $\times 20$ and $\times 40$ objective lens.

\section{Statistical analysis}

Results are presented as mean \pm standard error of mean (SEM). Differences among experimental groups were compared by one-way analysis of variance (ANOVA), followed by the least significant different test (LSD), and were considered significant when $P$ was less than 0.05 .

\section{Results}

\section{Characteristic features of $C$. asiatica extracts}

The major active compounds in HexE, EtAcE and MeE were identified by TLC as $\beta$-sitosterol, asiatic acid, and asiaticoside and madecassoside, respectively. None of these components were found in AqE.

\section{Effect of $C$. asiatica extracts on healing of incision wounds} As shown in Table 1, the tensile strengths of untreated and Tween $20^{\circledR}$-treated wounds were $14.99 \pm 1.72$ and $14.69 \pm 0.72 \mathrm{~N} / \mathrm{cm}^{2}$, respectively. A significant increase of tensile strength was observed in all extract-treated groups $(21.20 \pm 2.24, \quad 21.26 \pm 1.77, \quad 19.72 \pm 0.84$ and $21.05 \pm 1.90 \mathrm{~N} / \mathrm{cm}^{2}$ for HexE, EtAcE, MeE and AqE, respectively) compared to the vehicle-treated group. However, none of the tensile strengths in the extract-treated groups differed significantly from that of the NSStreated group. 
Table 1 Tensile strength of incision wounds treated with extracts of Centella asiatica on day 7 after wound infliction

\begin{tabular}{ll}
\hline Treatment group & Tensile strength $\mathbf{( N / \mathbf { c m } ^ { 2 } )}$ \\
\hline Untreated & $14.99 \pm 1.72$ \\
NSS & $17.62 \pm 1.42$ \\
Tween $20^{\circledR}$ & $14.69 \pm 0.72$ \\
Hexane extract & $21.20 \pm 2.24^{* *}$ \\
Ethyl acetate extract & $21.26 \pm 1.77^{* *}$ \\
Methanol extract & $19.72 \pm 0.84^{*}$ \\
Aqueous extract & $21.05 \pm 1.90^{* *}$
\end{tabular}

Values are presented as mean \pm S.E.M; $n=8 ;{ }^{*} P<0.05$ and ${ }^{* *} P<0.01$ vs. Tween $20^{\circledR}$.

\section{Effect of C. asiatica extracts on healing of burn wounds} Burn wound lesions

On Day 3, the wound in the untreated, NSS-treated and Tween $20^{\circledR}$-treated groups became swollen and bruised. In contrast, the wounds in all extract-treated groups showed a mild degree of swelling and the wound surface was rather dry. Most wounds in the EtAcE-treated group had begun to contract from the wound edge.

On Day 7, all wounds in the untreated, NSS-treated and Tween $20^{\circledR}$-treated groups were dark red, showed thickening of the skin at the wound site, and remained unchanged in size from the first day. Most of the wounds treated with the extracts showed wound contraction compared with the control group. The wounds in the MeE-treated group showed marked hair growth. Some wounds in the MeE- and AqE-treated groups had scabs covering the wound surface.

On Day 10, all wounds in the untreated, NSS-treated and Tween $20^{\circledR}$-treated groups showed moderate exudation and no hair growth, with scabs covering the wound surface. All wounds in the extract-treated groups had a dry surface, progressive wound contraction, and increased hair growth.

On Day 14, the last day of the experiment, all wounds in the untreated, NSS-treated and Tween $20^{\circledR}$-treated groups showed moderate exudation and scabs starting to separate from the wound surface. The wounds in the extract-treated groups showed a marked reduction in size and continuous growth of hair at the wound site. The wounds in the MeE- and AqE-treated groups showed the most marked reduction in wound size.

\section{Degree of healing of burn wounds}

The effects of $C$. asiatica extracts on the degree of healing of burn wounds are shown in Table 2. The degree of wound healing did not differ significantly among the untreated, NSS-treated and Tween $20^{\circledR}$-treated groups at every time point. On Day 3 after burn injury, only animals from the EtAcE-treated group had a higher degree
Table 2 Degree of healing of partial-thickness burn wounds treated with extracts of Centella asiatica

\begin{tabular}{lclll}
\hline \multirow{2}{*}{$\begin{array}{l}\text { Treatment } \\
\text { group }\end{array}$} & \multicolumn{4}{l}{ Degree of wound healing (\%) } \\
\cline { 2 - 5 } & Day 3 & Day 7 & Day 10 & Day 14 \\
\hline Untreated & $9.51 \pm 1.21$ & $14.27 \pm 2.10$ & $20.21 \pm 2.10$ & $25.36 \pm 1.81$ \\
NSS & $12.80 \pm 2.65$ & $19.64 \pm 2.34$ & $25.90 \pm 2.67$ & $31.85 \pm 2.66$ \\
Tween 20 & $10.05 \pm 1.50$ & $20.57 \pm 2.58$ & $27.69 \pm 2.39$ & $38.07 \pm 5.15$ \\
Hexane extract & $11.12 \pm 2.89$ & $26.02 \pm 4.02$ & $37.78 \pm 3.89^{*}$ & $53.87 \pm 4.64^{*}$ \\
Ethyl acetate & $18.13 \pm 2.29^{*}$ & $30.17 \pm 1.81^{*}$ & $38.11 \pm 2.30^{*}$ & $57.53 \pm 5.68^{*}$ \\
extract & & & & \\
Methanol extract & $11.71 \pm 1.94$ & $20.39 \pm 2.07$ & $28.94 \pm 2.55$ & $60.31 \pm 5.70^{* *}$ \\
Aqueous extract & $7.86 \pm 1.45$ & $19.98 \pm 2.23$ & $28.57 \pm 3.35$ & $59.82 \pm 8.31^{* *}$ \\
\hline
\end{tabular}

Values are presented as mean \pm S.E.M; $\mathrm{n}=8 ;{ }^{*} P<0.05$ and ${ }^{* *} P<0.01$ vs. Tween $20^{\circledR}$.

of wound healing compared to the vehicle control group. Similar results were observed on Day 7.

On Day 10 after burn injury, the degree of wound healing in animals treated with HexE or EtAcE was significantly higher than that in the vehicle control group. Moreover, the degree of wound healing in the HexEtreated group was not significantly different from that in the EtAcE-treated group.

On Day 14 after burn injury, the degree of wound healing in animals in all extract-treated groups was significantly higher than that in the vehicle control group. The degree of wound healing did not differ significantly among the extract-treated groups.

\section{Histopathological evaluation}

Histological features of normal skin are illustrated in Figure 1A. At the end of the experiment, on Day 14 after burn injury, the untreated burn wound showed prominent fibrinoid necrosis in the subepidermal region, which was characterized by permeation of collagen with fibrin and additional degenerative changes. Re-epithelialization was incomplete with little skin appendages. The wound surface was covered with exudates (Figure 1B).

The wounds in the NSS- and Tween $20^{\circledR}$-treated groups showed fibrinoid necrosis in some areas of the subepidermis. There were empty spaces in the dermal region of the Tween $20^{\circledR}$-treated group, indicating evidence of edema. Re-epithelialization was incomplete, but the wounds in the NSS-treated group looked better than those in the Tween $20^{\circledR}$-treated group (Figures $1 \mathrm{C}$ and $1 \mathrm{D}$, respectively). The wounds in all extract-treated groups showed fully developed epithelialization and keratinization. Skin appendages were almost normal. There was no noticeable necrosis or inflammation (Figures $1 \mathrm{E}, 1 \mathrm{~F}, 1 \mathrm{G}$ and $1 \mathrm{H}$ ).

\section{Discussion}

This study demonstrated that four different extracts of C. asiatica were able to increase the rate of wound 


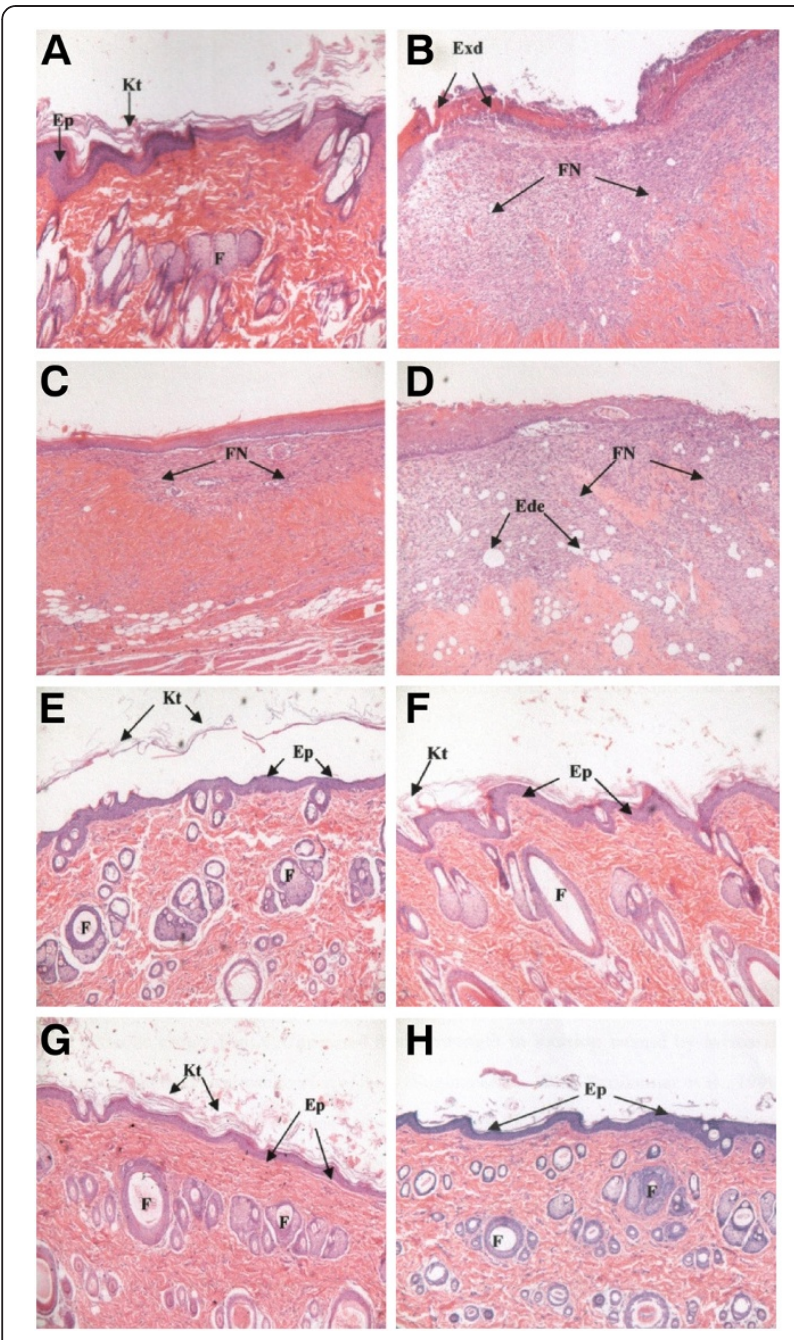

Figure 1 Histological features of partial-thickness burn wounds on day $\mathbf{1 4}$ after burn injury. Hematoxylin and eosin stains of $\mathbf{A}$ ) normal skin; B) untreated wound; C) NSS-treated wound; D) Tween 20-treated wound; E) hexane extract-treated wound; $\mathbf{F}$ ) ethyl acetate extract-treated wound; G) methanol extract-treated wound; H) water extract-treated wound. Ep: epidermis; Kt: keratin; Exd: exudates; FN: fibrinoid necrosis; Ede: edema; F: hair follicle.

healing for both incision and burn wounds. Seven days after inflicting the wound, the tensile strengths in the HexE, EtAcE, MeE and AqE-treated groups were significantly higher than that in the vehicle-treated group, but similar to the NSS-treated group. This observation may be due to the incision wound having minimal cell loss, since in this situation a tissue injury can be closed within 6-12 h if not contaminated [1]. Additionally, NSS, the most commonly used solution in clinical practice for wound irrigation, preserves the physiological condition and does not contain surfactants such as Tween $20^{\circledR}$, which has been postulated to cause skin injury [20]. Also, it is well known that collagen is the major protein component of wound connective tissue and is responsible for the tissue strength [21]; thus, the increased tensile strengths observed as a characteristic of the healing activity of extracts of $C$. asiatica may indicate an increase in collagen in the wound lesion. The present findings agree well with previous studies showing an increase of tensile strength or collagen synthesis in wounds treated by ethanolic extracts [22,23], asiaticoside $[11,24]$ or triterpenoids isolated from C. asiatica $[12,25]$.

In burn wounds, there is an extensive loss of cells and tissues compared to an incision wound, and this makes the repair process more complicated [26]. Wound healing activities of HexE, EtAcE, MeE and AqE were also observed, but at different time points. Animals treated with EtAcE, HexE, MeE and AqE had a significantly higher degree of healing on Days 3, 10 and 14 compared to the vehicle-treated group. However, on Day 14, there was a similar degree of wound healing in all the groups. All extract-treated wounds appeared to heal better than the controls based on gross examination, degree of wound healing, and histopathological evaluation.

Differences in the major constituents of the extracts may account for the results of the study. Asiatic acid, which was identified mainly in EtAcE, is the most potent component of $C$. asiatica for induction of expression of TNFAIP6, a hyaladherin involved in extracellular matrix remodeling and modulation of inflammation, in human fibroblasts [27]. Asiatic acid has also been found to increase collagen synthesis, which is important in the healing process $[12,25]$. These observations may explain the rapid onset on Day 3 and the sustained positive effects of EtAcE on burn wounds. The phases of inflammation and proliferation gradually increased between Days 7 and 10.

Significant effects of HexE appeared later, on Day 10 and Day 14. TLC showed that the major constituent of HexE was $\beta$-sitosterol, which has a potent angiogenic activity $[28,29]$. Thus, the healing activity of HexE observed in gross examination and histopathology could be partly due to angiogenic activity. The healing effects of $\mathrm{MeE}$ and $\mathrm{AqE}$ were significant on Day 14, indicating that the major constituents of these two extracts might exert their effect on the late phase of wound healing. Asiaticoside and madecassocide are triterpenoids found in MeE. Asiaticoside induces type I collagen synthesis in human dermal fibroblast cells via activation of the TGFbeta receptor I kinase-independent Smad signaling pathway [30] and also elevates antioxidant levels in a punch wound model, thereby promoting wound healing [31]. Madecassoside has also been shown to facilitate burn wound healing in mice [13].

$\beta$-sitosterol, asiatic acid, asiaticoside and madecassocide were not found in AqE using TLC but wound healing activity of this extract was seen on Day 14. Anand 
et al. found a high flavonoid content in an aqueous extract of $C$. asiatica and these molecules possess antioxidant property [32]. Antioxidants may help to control wound oxidative stress and thereby accelerate wound healing [33]. Therefore, flavonoids in the aqueous extract may have played an important role as anti-oxidants in the late stage of wound healing. These molecules could not be determined by the TLC technique used in the study. TLC is the most widely used method to detect substances because of its simplicity, but one of its limitations is its inability to detect certain molecules.

The results of this study support the notion that $C$. asiatica can promote wound healing by inhibiting inflammation, inducing collagen synthesis, promoting angiogenesis, inducing vasodilation, and reducing wound oxidative stress. In addition, C. asiatica extracts have been shown to affect cellular growth and proliferation in injured tissues. In an ideal wound healing situation, new tissue growth replaces damaged tissue causing functional or cosmetic impairment. The wound healing activity of C. asiatica extracts may be related to the growth factors such as endothelial growth factor, fibroblast growth factor and vascular endothelial growth factor. A further study on the effects of $C$. asiatica extracts on these growth factors is needed to clarify the mechanism of wound healing. Microcirculatory studies are also warranted to investigate the anti-inflammatory activity of EtAcE of $C$. asiatica, which was seen early during the healing process.

\section{Conclusions}

The present study demonstrates the wound healing effects of C. asiatica extracts for both incision and burn wounds. All types of extracts (HexE, EtAcE, MeE and $\mathrm{AqE})$ exerted wound healing activity, but EtAcE containing asiatic acid was the most active extract for wound healing.

\section{Abbreviations}

C. asiatica: Centella asiatica; NSS: Normal saline solution; TLC: Thin-layer chromatography; HexE: Hexane extract; EtAcE: Ethyl acetate extract; MetE: Methanol extract; AqE: Aqueous extract.

\section{Competing interests}

All authors declare that they have no competing interests.

\section{Authors' contributions}

JS participated in the design of the experiments, conducted and analyzed the gross and histopathological data, and drafted the manuscript. MK was responsible for preparing incision and burn wounds and for statistical analysis. BT prepared the extracts and acquired animal data. MT conceived and designed the study, analyzed the data and critically revised the manuscript. All authors have read and approved the final manuscript.

\section{Acknowledgements}

The present study was supported by the Graduate School of Chulalongkorn University and the National Research Council of Thailand, Bangkok, Thailand. The authors would like to thank Dr. lan S. Haworth (University of South California) for his suggestions and comments on the manuscript.

\section{Author details}

'Department of Physiology, Faculty of Medicine, Chulalongkorn University, Patumwan, Bangkok 10330, Thailand. ${ }^{2}$ Inter-disciplinary Program of Pharmacology, Graduate School, Chulalongkorn University, Patumwan, Bangkok 10330, Thailand. ${ }^{3}$ Department of Pharmacology and Physiology, Faculty of Pharmaceutical Sciences, Chulalongkorn University, Patumwan, Bangkok 10330, Thailand. ${ }^{4}$ Present address: Faculty of Pharmaceutical Sciences, Burapha University, Chonburi 20131, Thailand.

Received: 8 January 2012 Accepted: 3 July 2012

Published: 20 July 2012

\section{References}

1. Leaper DJ, Gottrup F: Surgical wounds. In Wounds: Biology and management. Edited by Leaper DJ, Harding KG. Hong Kong: Oxford University Press; 1998:23-40.

2. Mayo clinic staff: Burns. http://www.mayoclinic.com/health/burns/DS01176/ METHODS=print accessed 5 Dec 2011

3. World Health Organization: National policy on traditional medicine and regulation of herbal medicine-report of a WHO global survey. http://apps.who. int/medicinedocs/en/d/Js7916e/ (accessed 10 March 2012).

4. Meir K, Nanney LB: Emerging new drugs for wound repair. Expert Opin Emerg Drugs 2006, 11:23-37.

5. Somchit MN, Sulaiman MR, Zuraini A, Samsuddin L, Somchit N, Israf DA, Moin S: Antinociceptive and anti-inflammatory effects of Centella asiatica. Indian J Pharmacol 2004, 36:377-380.

6. Cheng $\mathrm{CL}$, Koo MWL: Effects of Centella asiatica on ethanol induced gastric mucosal lesions in rats. Life Sci 2000, 67:2647-2653.

7. Brinkhaus B, Lindner M, Schuppan D, Hahn EG: Chemical, pharmacological and clinical profile of the East Asian medical plant Centella asiatica. Phytomed 2000, 7:427-448.

8. Kosalwatna S, Shaipanich C, Bhanganada K: The effect of one percent Centella asiatica cream on chronic ulcers. Siriraj Hosp Gaz 1988, 40:455-460.

9. Chen YJ, Dai YS, Chen BF, Chang A, Chen HC, Lin YC, Chang KH, Lai YL, Chung CH, Lai YJ: The effect of tetrandrine and extracts of Centella asiatica on acute radiation dermatitis in rats. Biol Pharm Bull 1999 22:703-706

10. Shetty BS, Udupa SL, Udupa AL, Somayaji SN: Effect of Centella asiatica L (Umbelliferae) on normal and dexamethasone suppressed wound healing in Wistar Albino rats. Int J Low Extrem Wounds 2006, 5:137-143.

11. Shukla A, Rasik AM, Jain GK, Shankar R, Kulshrestha DK, Dhawan BN: In vitro and in vivo wound healing activity of asiaticoside isolated from Centella asiatica. J Ethnopharmacol 1999, 65:1-11.

12. Maquart FX, Chastang F, Simeon A, Birembaut P, Gillery P, Wegrowski Y: Triterpenes from Centella asiatica stimulate extracellular matrix accumulation in rat experimental wounds. Eur J Dermatol 1999, 9:289-296.

13. Liu M, Dai Y, Li Y, Luo Y, Huang F, Gong Z, Meng Q: Madecassoside isolated from Centella asiatica herbs facilitates burn wound healing in mice. Planta Med 2008, 74:809-815.

14. Paocharoen V: The efficacy and side effects of oral Centella asiatica extract for wound healing promotion in diabetic wound patients. $J$ Med Assoc Thai 2010, 93(Suppl 7):S166-S170.

15. Kilkenny C, Browne WJ, Cuthill IC, Emerson M, Altman DG: Improving Bioscience Research Reporting: The ARRIVE Guidelines for Reporting Animal Research. PLoS Biol 2010, 8(6):e1000412.

16. Baie $\mathrm{S}, \mathrm{Hj}$, Sheikh KA: The wound healing properties of Channa striatuscetrimide cream-tensile strength measurement. J Ethnopharmacol 2000, 71:93-10.

17. Somboonwong J, Thanamittramanee S, Jariyapongskul A, Patumraj S: Therapeutic effects of Aloe vera on cutaneous microcirculation and wound healing in second degree burn model in rats. J Med Assoc Thai 2000, 83:417-425.

18. Zawacki BE: Reversal of capillary stasis and prevention of necrosis in burns. Ann Surg 1974, 180:98-102.

19. Reddy JS, Rao PR, Reddy MS: Wound healing effects of Heliotropium indicum, Plumbago zeylanicum and Acalypha indica in rats. J Ethnopharmacol 2002, 79:249-251.

20. van Ruissen F, Le M, Carroll JM, van der Valk PG, Schalkwijk J: Differential effects of detergents on keratinocyte gene expression. J Invest Dermatol 1998, 110:358-363. 
21. locono JA, Ehrlich HP, Gottrup F, Leaper DJ: The biology of healing. In Wounds: Biology and Management. Edited by Leaper DJ, Harding KG. Hong Kong: Oxford University Press; 1998:10-22.

22. Suguna L, Sivakumar P, Chandrakasan G: Effects of Centella asiatica extract on dermal wound healing in rats. Indian J Exp Biol 1996, 34:1208-1211.

23. Sunikumar P, Parameshwaraiah S, Shivakumar HG: Evaluation of topical formulations of aqueous extract of Centella asiatica on open wounds in rats. Indian J Exp Biol 1998, 36:569-572.

24. Lu L, Ying K, Wei S, Fang Y, Liu Y, Lin H, Ma L, Mao Y: Asiaticoside induction for cell-cycle progression, proliferation and collagen synthesis in human dermal fibroblasts. Int J Dermatol 2004, 43:801-807.

25. Bonte F, Dumas M, Chaudagne C, Meybeck A: Influence of asiatic acid, madecassic acid, and asiaticoside on human collagen I synthesis. Planta Med 1993, 60:133-135.

26. Cotran RS, Kumar V, Robbins SL: Inflammation and repair. In Robbins Pathologic Basis of Disease. 5th edition. Edited by Cotran RS, et al. Philadelphia: W.B. Saunders; 1994:85-91.

27. Coldren CD, Hashim P, Ali JM, Oh HK, Sinskey AJ, Rha C: Gene expression changes in the human fibroblast induced by Centella asiatica triterpenoids. Planta Med 2003, 69:725-732.

28. Moon EJ, Lee YM, Lee OH, Lee MJ, Lee SK, Chung MH, Park YI, Sung CK, Choi JS, Kim KW: A novel angiogenic factor derived from Aloe vera gel: $\beta$-sitosterol, a plant sterol. Angiogenesis 1999, 3:117-123.

29. Choi S, Kim KW, Choi JS, Han ST, Part YI, Lee SK, Kim JS, Chung MH: Angiogenic activity of $\beta$-sitosterol in the ischaemia/reperfusion-damaged brain of Mongolian Gerbil. Planta Med 2002, 68:330-335.

30. Lee J, Jung E, Kim Y, Park J, Park J, Hong S, Kim J, Hyun C, Kim YS, Park D: Asiaticoside induces human collagen I synthesis through TGFbeta receptor I kinase (TbetaRI kinase)-independent Smad signaling. Planta Med 2006, 72:324-328.

31. Shukla A, Rasik AM, Dhawan BN: Asiaticoside induced elevation of antioxidant levels in healing wound. Phytother Res 1999, 13:50-54

32. Anand T, Naika M, Kumar PG, Khanum F: Antioxidant and DNA damage preventive properties of Centella asiatica (L) Urb. Phcog J 2010, 2:53-58.

33. Fitzmaurice SD, Sivamani RK, Isseroff RR: Antioxidant therapies for wound healing: A clinical guide to currently commercially available products. Skin Pharmacol Physiol 2011, 24:113-126. doi:10.1159/000322643.

doi:10.1186/1472-6882-12-103

Cite this article as: Somboonwong et al: Wound healing activities of different extracts of Centella asiatica in incision and burn wound models: an experimental animal study. BMC Complementary and Alternative Medicine 2012 12:103.

\section{Submit your next manuscript to BioMed Central and take full advantage of:}

- Convenient online submission

- Thorough peer review

- No space constraints or color figure charges

- Immediate publication on acceptance

- Inclusion in PubMed, CAS, Scopus and Google Scholar

- Research which is freely available for redistribution

Submit your manuscript at www.biomedcentral.com/submit
Biomed Central 